\title{
Video Article \\ Performing Vaginal Lavage, Crystal Violet Staining, and Vaginal Cytological Evaluation for Mouse Estrous Cycle Staging Identification
}

\author{
Ashleigh C. McLean ${ }^{1,2,3}$, Nicolas Valenzuela ${ }^{3,4}$, Stephen Fai ${ }^{3,4}$, Steffany A.L. Bennett ${ }^{1,3}$ \\ ${ }^{1}$ Department of Biochemistry, Microbiology and Immunology, Neural Regeneration Laboratory and Ottawa Institute of Systems Biology \\ ${ }^{2}$ Department of Cellular and Molecular Medicine, University of Ottawa \\ ${ }^{3}$ CIHR Program in Neurodegenerative Lipidomics, University of Ottawa \\ ${ }^{4}$ Carleton Immersive Media Studio, Azrieli School of Architecture and Urbanism
}

Correspondence to: Steffany A.L. Bennett at sbennet@uottawa.ca

URL: https://www.jove.com/video/4389

DOI: doi:10.3791/4389

Keywords: Medicine, Issue 67, Biochemistry, Immunology, Microbiology, Physiology, Anatomy, estrous cycle, vaginal cytology, hormonal status, murine reproduction, 17-beta-estradiol, progesterone, luteinizing hormone, follicle-stimulating hormone, prolactin

Date Published: 9/15/2012

Citation: McLean, A.C., Valenzuela, N., Fai, S., Bennett, S.A. Performing Vaginal Lavage, Crystal Violet Staining, and Vaginal Cytological Evaluation for Mouse Estrous Cycle Staging Identification. J. Vis. Exp. (67), e4389, doi:10.3791/4389 (2012).

\section{Abstract}

A rapid means of assessing reproductive status in rodents is useful not only in the study of reproductive dysfunction but is also required for the production of new mouse models of disease and investigations into the hormonal regulation of tissue degeneration (or regeneration) following pathological challenge. The murine reproductive (or estrous) cycle is divided into 4 stages: proestrus, estrus, metestrus, and diestrus. Defined fluctuations in circulating levels of the ovarian steroids $17-\beta$-estradiol and progesterone, the gonadotropins luteinizing and follicle stimulating hormones, and the luteotropic hormone prolactin signal transition through these reproductive stages. Changes in cell typology within the murine vaginal canal reflect these underlying endocrine events. Daily assessment of the relative ratio of nucleated epithelial cells, cornified squamous epithelial cells, and leukocytes present in vaginal smears can be used to identify murine estrous stages. The degree of invasiveness, however, employed in collecting these samples can alter reproductive status and elicit an inflammatory response that can confound cytological assessment of smears. Here, we describe a simple, non-invasive protocol that can be used to determine the stage of the estrous cycle of a female mouse without altering her reproductive cycle. We detail how to differentiate between the four stages of the estrous cycle by collection and analysis of predominant cell typology in vaginal smears and we show how these changes can be interpreted with respect to endocrine status.

\section{Video Link}

The video component of this article can be found at https://www.jove.com/video/4389/

\section{Protocol}

\section{Preparing Reagents}

1. For sterile vaginal lavage, autoclave double distilled water $\left(\mathrm{ddH}_{2} \mathrm{O}\right)$ and store in a tightly sealed container at room temperature until needed.

2. For cytological assessment, add $0.1 \mathrm{~g}$ of crystal violet powder to $100 \mathrm{ml}$ of dd $\mathrm{H}_{2} \mathrm{O}$. Mix well. Crystal violet stain $(0.1 \%)$ can be stored in a tightly sealed container at room temperature until needed.

\section{Collecting Vaginal Cells (Vaginal Lavage)}

1. Place a latex bulb on the end of a sterile $200 \mu \mathrm{l}$ tip and draw up approximately $100 \mu \mathrm{l}$ of sterile $\mathrm{ddH}_{2} \mathrm{O}$ using the gradations on the tip as a volume guideline.

2. Lift the mouse out of her cage and place her on the cage hopper (lid) with her hind/rear end towards you.

3. Firmly grasp the tail and elevate the rear end. The mouse will now have only her front paws grasping the hopper. At this point the mouse may urinate. If so, wait until urination stops. Should there be urine left at the entrance to the vaginal canal, you may want to rinse the opening with excess $\mathrm{ddH}_{2} \mathrm{O}$ using a separate tip (i.e., not your sample collection tip).

4. Place the end of the $\mathrm{ddH}_{2} \mathrm{O}$-filled tip at the opening of the vaginal canal taking care to not penetrate the orifice as vaginal (and cervical) stimulation can induce pseudopregnancy in rats ${ }^{1,2}$. Recent reports suggest mice are less susceptible to this effect nonetheless care should be taken to minimize the degree of invasiveness in repeated analyses ${ }^{3}$.

5. Gently depress the bulb to expel a quarter to half of the volume of water $(\sim 25-50 \mu \mathrm{l})$ at the opening of vaginal canal. The liquid will spontaneously aspirate into the canal without tip insertion. Slowly release the pressure exerted on the bulb. The fluid will withdraw back into the tip. Avoid releasing pressure too quickly to prevent aspiration of fluid into the bulb. A filtered tip may be useful for this purpose.

6. Repeat the previous step 4-5 times using the same tip, bulb, and fluid to obtain a sufficient number of cells in a single sample. 
7. Place the fluid on glass slide, and allow the smear to completely dry at room temperature. Once dry, these estrous smears can be stained immediately or stored and stained at a later date.

\section{Cytological Staining using Crystal Violet ${ }^{4}$}

1. Place the dry slide in a coplin jar (or other comparable staining vessel) containing the crystal violet stain for $1 \mathrm{~min}$.

2. Remove to a second coplin jar containing $\mathrm{ddH}_{2} \mathrm{O}$. Wash the slide with $\mathrm{dd}_{2} \mathrm{O}$ for 1 min. Repeat.

3. Remove the excess $\mathrm{ddH}_{2} \mathrm{O}$ from the edges of the slide with a light-duty tissue wiper, avoiding contact with the stained smear.

4. Pipette approximately $15 \mu \mathrm{l}$ of glycerol on top of the smear and coverslip. Alternatively, other histological mounting reagents can be utilized to obtain a more permanent, non-diffusing stain.

* The staining method described here is the simplest procedure that can be performed in any laboratory. Other methods can provide additional details. For example, using Papanicolaou staining, the maturity of nucleated epithelial cells can be distinguished with less mature cells stained turquoise and more mature cells pink- or orange-stained. These differences can be used to stage early or late proestrus. ${ }^{4}$

\section{Vaginal Cytology}

1. Examine the smear under light microscopy to determine cell types present. Microscopic examination should be done immediately after staining as the crystal violet will diffuse from the cells over time when using glycerol for coverslipping. Photomicrographs should be taken at time of analysis to document cytology.

2. Start by examining the entire smear at a lower magnification. Select a representative area and move to a higher magnification. You will see cornified squamous epithelial cells, leukocytes, and/or nucleated epithelial cells (representative results, Figure 1A-C). The ratio of cells present will allow you to determine the estrous stage of your mouse at time of sample collection (representative results, Figure 1D-G) and her immediate hormonal status (discussion, Figure 2).

\section{Representative Results}

Cytology: Three primary cell types can be detected in vaginal smear samples: (1) nucleated epithelial cells (Figure 1A), (2) cornified squamous epithelial cells (Figure 1B), and (3) leukocytes (Figure 1C). Nucleated epithelial cells have a lightly stained cytoplasm, darker stained plasma membrane, and an oval nucleus (Figure 1A). Cornified squamous epithelial cells are uniformly stained, more polygonal in shape than their nucleated epithelial predecessors, and lack a nucleus (Figure 1B). Polymorphonuclear leukocytes can be distinguished from epithelial cells by their irregular shape, darkly stained polymorphic nuclei, and small size (Figure 1C, black arrows). Should urine contamination be present in the smear, uric acid crystals are readily detected by their crystalline structures dissimilar to any expected cell types (Figure 3). Should this occur, and obscure detection of predominant cell type, the smear should be discarded and not used for staging purposes.

Staging: The relative ratio of cell types observed in smears can be used to identify the stage of the estrous cycle of your mouse on the day of sample collection (Figure 1D-G). During proestrus, cells are almost exclusively clusters of round, well-formed nucleated epithelial cells (Figure 1D, representative cell indicated by white arrow). During estrus, cells are predominantly cornified squamous epithelial cells, present in densely packed clusters (Figure 1E, representative cell indicated by arrowhead). During metestrus, small darkly stained leukocytes predominate (Figure 1F, representative cell indicated by black arrow). Cornified squamous epithelial cells may be observed, often in fragments, (Figure $1 F$, representative cell indicated by black arrowhead). During diestrus, rare cornified squamous epithelial cells may still be present (Figure 1G, representative cell indicated by black arrowhead), however leukocytes still predominate (Figure 1G, representative cell indicated by black arrow). Metestrus can be distinguished from diestrus by the appearance of nucleated epithelial cells in diestrus (Figure 1G, representative cell indicated by white arrow). 


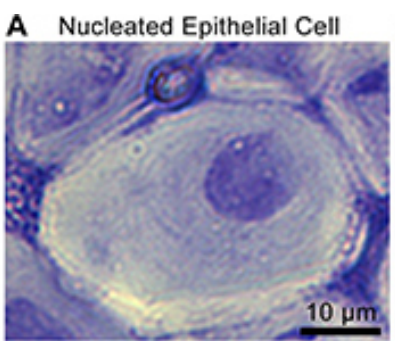

\section{Proestrus}

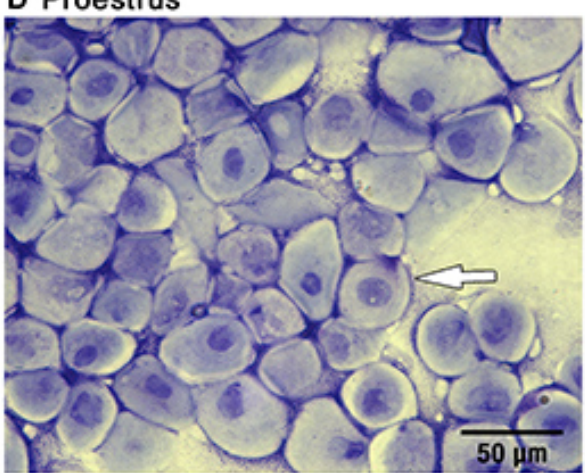

\section{F Metestrus}

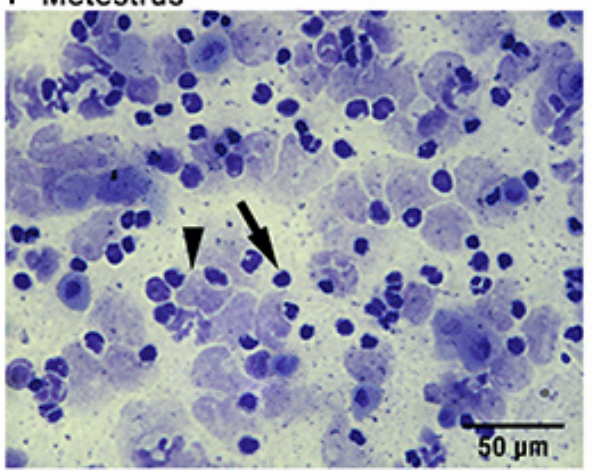

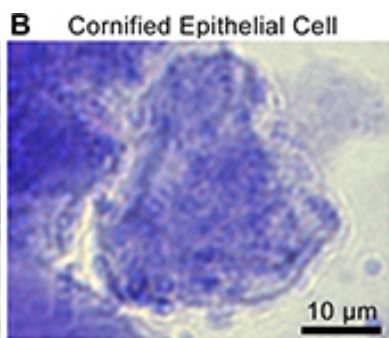

C Leukocytes

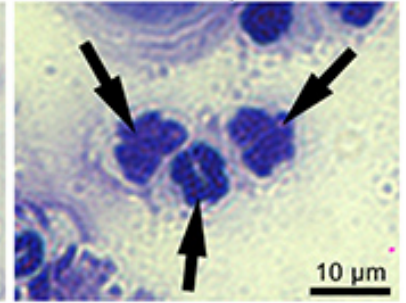

\section{E Estrus}

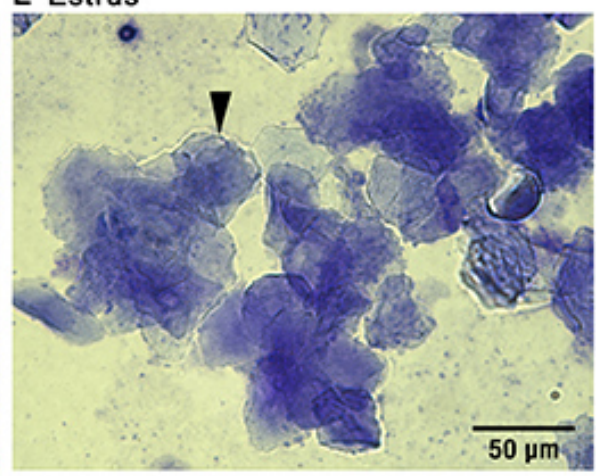

\section{G Diestrus}

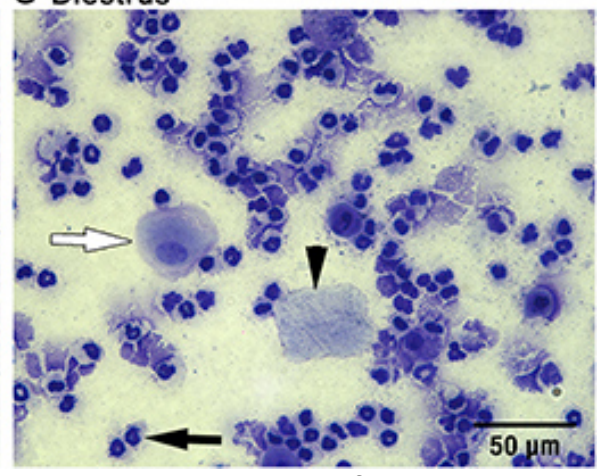

Figure 1. Cytological assessment of vaginal smears can be used to identify estrous stage. Three main cell types are detected in vaginal smear samples: (A) nucleated epithelial cells, (B) cornified squamous epithelial cells, and (C) leukocytes. The ratio of these cell types present in the smear can be used to identify mice in (D) proestrus, (E) estrus, (F) metestrus, or (G) diestrus as described in representative results. Black arrowheads in $E, F$ and $G$ point to representative cornified squamous epithelial cells. Black arrows in $C, F$ and $G$ point to representative leykocytes. White arrows in $\mathrm{D}$ and $\mathrm{G}$ highlight representative nucleated epithelial cells. 


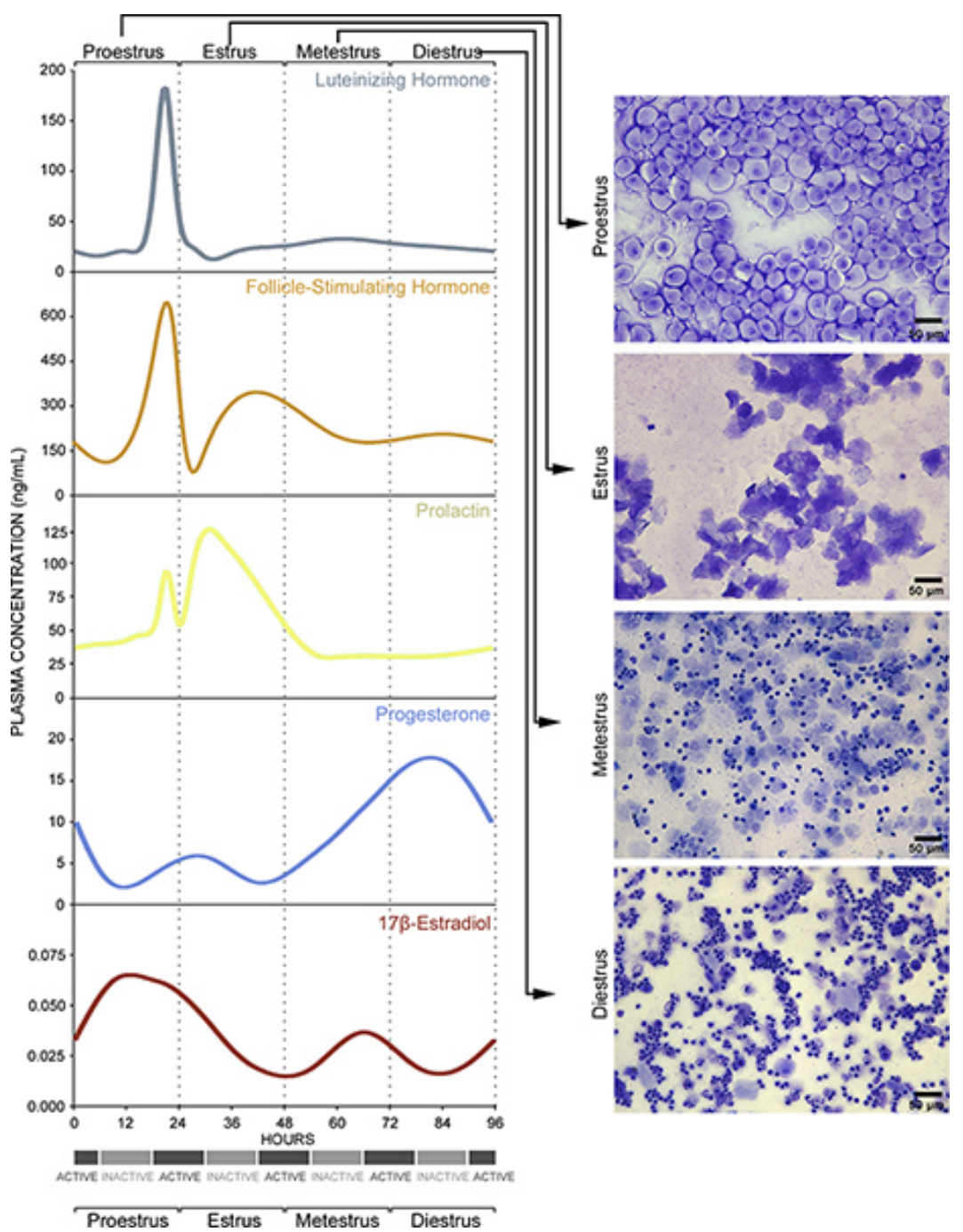

Figure 2. Vaginal smear cytology reflects underlying endocrine events. Details are also provided in Discussion. Click here to view larger figure.
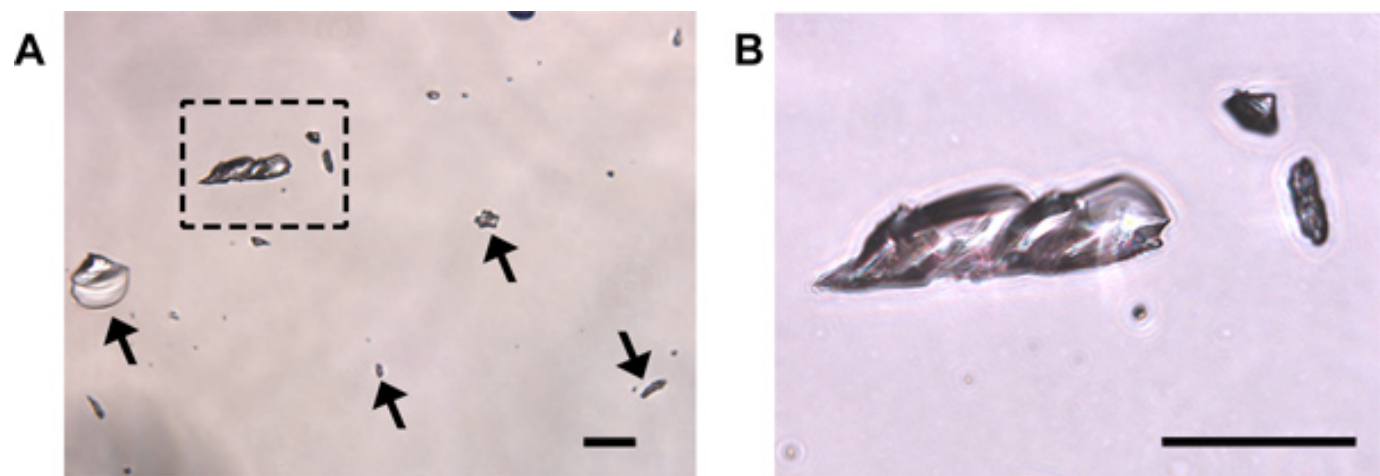

Figure 3. Uric acid crystals may be present following crystal violet staining of urine-contaminated samples. (A) Crystals are transparent and can be of various sizes (arrows and boxed region magnified in (B)). No cells are present in this field. Should uric acid crystal contamination within fields used for cytological staining be present, it may be difficult to accurately identify cell types present and the smear should be discarded. Scale bars $=50 \mu \mathrm{m}$.

\section{Discussion}

These changes in cell typology are indicative of underlying endocrine events. The proestrus phase of the estrous cycle corresponds to the human follicular phase of the menstrual cycle ${ }^{5}$ and is defined by a pre-ovulatory increase in circulating 17- $\beta$-estradiol levels ${ }^{6}$, as well as a small surge in prolactin ${ }^{7}$ (Figure 2, Proestrus, left panel). The increase in 17- $\beta$-estradiol indirectly stimulates gonadotropin-releasing hormone neurons in the hypothalamus and septum that, in turn, activate responsive cells in the anterior pituitary to release luteinizing hormone and 
follicle-stimulating hormone into the circulation ${ }^{8,9}$ (Figure 2, Proestrus, left panel). In vaginal smears taken from animals in proestrus, cells are almost exclusively oval nucleated epithelial cells (Figure 1D, Figure 2, Proestrus, right panel). The peak in follicle-stimulating hormone levels signals ovulation and entry into estrus ${ }^{10,11}$. During estrus, 17- $\beta$-estradiol levels decline and prolactin levels peak ${ }^{6,7}$ (Figure 2, Estrus, left panel). Vaginal smears are characterized by almost exclusive detection of irregular-shaped cornified squamous epithelial cells often in clumps (Figure 1E, Figure 2, Estrus, right panel). Entry into metestrus coincides with a continuous rise in progesterone hormone levels ${ }^{6}$ and corresponds to the beginning of human luteal phase ${ }^{12}$ (Figure 2, Metestrus, left panel). As progesterone levels start to rise and there is a small surge in 17- $\beta$ estradiol levels in response to corpus luteum activation ${ }^{6,13,14}$ (Figure 2, Metestrus, left panel). The cell types present in vaginal smears during this stage are fragmented, cornified epithelial cells and smaller darker stained leukocytes (Figure 1F, Figure 2, Metestrus, right panel). Finally, entry into diestrus in mice occurs and circulating progesterone levels peak ${ }^{6}$, corresponding to the human late luteal phase ${ }^{12}$. Regression of the corpus luteum leads to a subsequent sharp decline in progesterone levels ${ }^{15,16}$ (Figure 2, Diestrus, left panel). Leukocytes predominate in smears during diestrus. The frequency of cornified epithelial cells is reduced and nucleated epithelial cells begin to be detected just prior to transition to proestrus (Figure 1G, Figure 2, Diestrus, right panel).

In summary, this simple, routine protocol can be used to estimate daily hormonal fluctuations and establish estrous stage in experimental mice without altering reproductive status if the following precautions are taken. Sampling should be performed no more than once daily using the non-invasive protocol described here as compared to repeated penetration of the vaginal canal, aspiration, and agitation. This can cause vaginal irritation resulting in an inflammatory response ${ }^{17}$ resulting in leukocytes and other cell types to be present in smears that may confound cytological assessment. Moreover, even in colony-housed females, it is normal to see extended diestrus and estrus stages in different mice as well induction of anestrous ${ }^{18}$ and this identification is useful in the interpretation of hormonal impact in reproductive, gender, and disease studies. Variability in cycle length is also introduced with age and by housing differences within colonies (individual or group-housing) of females ${ }^{7,19-21}$. Females housed in female-only colonies can cease cycling and enter a state of prolonged diestrus ${ }^{18,22,23}$ although cycling can be re-instated by exposure to cages pretreated with male urine to elicit cycling ${ }^{24,25}$. Thus, to establish individual cycle lengths for a given mouse, it is recommended that the non-invasive assessments described here be performed daily, with care, until two complete cycles are observed.

\section{Disclosures}

The authors declare no conflict of interest. All experiments on animals were performed in strict accordance with the guidelines and regulations set forth by the University of Ottawa Animal Care Committee and the Canadian Council on Animal Care.

\section{Acknowledgements}

We would like to thank Marc Leonard from Carleton Immersive Media Studio for expert technical assistance in video production and editing and Dr. Martin Bertrand from Carleton Immersive Media Studio / Neural Regeneration Laboratory for visual model assistance. The authors gratefully acknowledge the expert advice of Dr. Marilyn Keaney and all of her dedicated staff at the University of Ottawa Animal Care and Veterinary Services. This work was funded by the Canadian Institute of Health Research (CIHR, MOP 62826) to SALB, the CIHR Institute of Aging and Strategic Training Initiative in Health Research/CIHR Training Program in Neurodegenerative Lipidomics (TGF 96121) to SALB and SF, Canadian Foundation for Innovation to SF, Ontario Innovation Trust to SF, and Autodesk Research to SF. ACM receives a CIHR Banting and Best doctoral award. NV receives a post-professional fellowship from Institute of Aging and ClHR Training Program in Neurodegenerative Lipidomics.

\section{References}

1. Adler, N.T. \& Zoloth, S.R. Copulatory behavior can inhibit pregnancy in female rats. Science. 168, 1480-1482 (1970).

2. Adler, N.T., Resko, J.A., \& Goy, R.W. The effect of copulatory behavior on hormonal change in the female rat prior to implantation. Physiology \& behavior. 5, 1003-1007 (1970).

3. Yang, J.J., Larsen, C.M., Grattan, D.R., \& Erskine, M.S. Mating-induced neuroendocrine responses during pseudopregnancy in the female mouse. Journal of neuroendocrinology. 21, 30-39 (2009).

4. Hong, H., et al. Changes in the mouse estrus cycle in response to BRCA1 inactivation suggest a potential link between risk factors for familial and sporadic ovarian cancer. Cancer research. 70, 221-228 (2010).

5. Hawkins, S.M. \& Matzuk, M.M. The menstrual cycle: basic biology. Annals of the New York Academy of Sciences. 1135, 10-18 (2008).

6. Walmer, D.K., Wrona, M.A., Hughes, C.L., \& Nelson, K.G. Lactoferrin expression in the mouse reproductive tract during the natural estrous cycle: correlation with circulating estradiol and progesterone. Endocrinology. 131, 1458-1466 (1992).

7. Parkening, T.A., Collins, T.J., \& Smith, E.R. Plasma and pituitary concentrations of LH, FSH, and prolactin in aging C57BL/6 mice at various times of the estrous cycle. Neurobiology of aging. 3, 31-35 (1982).

8. Sarkar, D.K., Chiappa, S.A., Fink, G., \& Sherwood, N.M. Gonadotropin-releasing hormone surge in pro-oestrous rats. Nature. 264, 461-463 (1976).

9. Rajendren, G. \& Gibson, M.J. A confocal microscopic study of synaptic inputs to gonadotropin-releasing hormone cells in mouse brain: regional differences and enhancement by estrogen. Neuroendocrinology. 73, 84-90 (2001).

10. Kumar, T.R., Wang, Y., Lu, N., \& Matzuk, M.M. Follicle stimulating hormone is required for ovarian follicle maturation but not male fertility. Nature genetics. 15, 201-204 (1997).

11. Montgomery, V., Loutradis, D., Tulchinsky, D., \& Kiessling, A. FSH-induced ovulation in intact and hypophysectomized mice. Journal of reproduction and fertility. 84, 1-6 (1988).

12. Mihm, M., Gangooly, S., \& Muttukrishna, S. The normal menstrual cycle in women. Animal reproduction science. 124, 229-236 (2011).

13. Appelgren, L.E. Histochemical demonstration of drug interference with progesterone synthesis. Journal of reproduction and fertility. 19, 185-186 (1969).

14. Sander, V.A., Facorro, G.B., Piehl, L., Rubin de Celis, E., \& Motta, A.B. Effect of DHEA and metformin on corpus luteum in mice. Reproduction. 138, 571-579 (2009). 
15. Stocco, C., Telleria, C., \& Gibori, G. The molecular control of corpus luteum formation, function, and regression. Endocrine reviews. $\mathbf{2 8}$, 117-149 (2007).

16. Rudolph, M., et al. Induction of overt menstruation in intact mice. PLoS One. 7, e32922 (2012).

17. Yano, J., Lilly, E., Barousse, M., \& Fidel, P.L., Jr. Epithelial cell-derived S100 calcium-binding proteins as key mediators in the hallmark acute neutrophil response during Candida vaginitis. Infection and immunity. 78, 5126-5137 (2010).

18. Whitten, W.K. Occurrence of anoestrus in mice caged in groups. The Journal of endocrinology. 18, 102-107 (1959).

19. Lamond, D.R. Effect of stimulation derived from other animals of the same species on oestrous cycles in mice. The Journal of endocrinology. 18, 343-349 (1959).

20. Nelson, J.F., Felicio, L.S., Randall, P K., Sims, C,. \& Finch, C.E. A longitudinal study of estrous cyclicity in aging C57BL/6J mice: I. Cycle frequency, length and vaginal cytology. Biology of reproduction. 27, 327-339 (1982).

21. Felicio, L.S., Nelson, J.F., \& Finch, C.E. Longitudinal studies of estrous cyclicity in aging C57BL/6J mice: II. Cessation of cyclicity and the duration of persistent vaginal cornification. Biology of reproduction. 31, 446-453 (1984).

22. Van Der Lee, S. \& Boot, L.M. Spontaneous pseudopregnancy in mice. II. Acta physiologica et pharmacologica Neerlandica. 5, 213-215 (1956).

23. Van Der Lee, S. \& Boot, L.M. Spontaneous pseudopregnancy in mice. Acta physiologica et pharmacologica Neerlandica. 4, 442-444 (1955).

24. Armaiz-Pena, G.N., et al. Estrous cycle modulates ovarian carcinoma growth. Clinical cancer research : an official journal of the American Association for Cancer Research. 15, 2971-2978 (2009).

25. Jemiolo, B., Harvey, S., \& Novotny, M. Promotion of the Whitten effect in female mice by synthetic analogs of male urinary constituents. Proceedings of the National Academy of Sciences of the United States of America. 83, 4576-4579 (1986). 